\title{
Autonomic Nervous System Dysregulation: Breathing and Heart Rate Perturbation During Wakefulness in Young Girls with Rett Syndrome
}

\author{
DEBRA E. WEESE-MAYER, STEVEN P. LIESKE, CHRISTINA M. BOOTHBY, ANNA S. KENNY, HEATHER L. BENNETT, \\ JEAN M. SILVESTRI, AND JAN-MARINO RAMIREZ
}

Pediatric Respiratory Medicine [D.E.W.-M., C.M.B., A.S.K., H.L.B., J.M.S.], Rush University Medical Center, Chicago, Illinois, 60612; Organismal Biology and Anatomy [S.P.L., J.-M.R.], University of Chicago Pritzker School of Medicine, Chicago, Illinois, 60637

\begin{abstract}
This study characterizes cardiorespiratory dysregulation in young girls with $M E C P 2$ mutation-confirmed Rett syndrome (RS). Respiratory inductance plethysmography of chest/abdomen and ECG was obtained during daytime wakefulness in 47 girls with MECP2 mutation-confirmed RS and 47 age-, gender-, and ethnicitymatched controls (ages 2-7 y). An in-home breath-to-breath and beat-to-beat characterization was conducted and revealed that breathing was more irregular, with an increased breathing frequency, mean airflow, and heart rate in RS versus controls. There was a decreased correlation between normal breathing and heart rate variability, and an exaggerated increase in heart rate response to breathholds in RS versus controls. We conclude that girls with RS have cardiorespiratory dysregulation during breathholds as well as during "normal" breaths and during breaths before and subsequent to breathholds. This dysregulation may offer insight into the mechanisms that render girls with RS more vulnerable to sudden death. (Pediatr Res 60: 443-449, 2006)
\end{abstract}

$\mathrm{R}^{\mathrm{s}}$ $\mathrm{S}$ is one of a growing number of disorders characterized by autonomic nervous system dysfunction/dysregulation (1). Diagnosis of RS is based on clinical criteria (2-4), with more than $85 \%$ of identified girls having mutations in MECP2 on the $\mathrm{X}$ chromosome (5; B. Roa, personal communication). The RS phenotype includes normal development until 6-18 mo of age, then regression with slowing of head circumference growth, loss of language, development of stereotypical hand movements, gait and truncal apraxia, EEG abnormalities, seizures, spasticity, and scoliosis (2).

Breathing irregularities consistent with autonomic dysregulation in RS include characteristic patterns variably described as hyperventilation, Valsalva maneuvers, apnea, apneusis, breathholding, and rapid shallow breathing (6-17). These irregularities are reported to occur near-exclusively during

Received March 29, 2006; accepted June 7, 2006.

Correspondence: Debra E. Weese-Mayer, M.D., Pediatric Respiratory Medicine at Rush Children's Hospital, 1653 West Congress Parkway, Chicago, IL 60612; e-mail: Debra_E_Weese-Mayer@rsh.net

VivoMetrics, Inc. provided the LifeShirt vest technology for this study. The Rett Syndrome Research Foundation provided grant support (D.E.W.-M.).

This study was presented in part at the Society for Pediatric Research Annual Meeting in Washington, DC, May 2005.

The online version of this article contains supplemental material at Pediatric Research online (http://www.pedresearch.org).

DOI: 10.1203/01.pdr.0000238302.84552.d0 wakefulness $(8,17)$. Age may play a role, as more breathholds and forceful breathing are reported in 5-10-y-old patients compared with more of a Valsalva pattern in young adults (13). Conclusions regarding imbalance of sympathovagal input have been made primarily from heart rate and blood pressure monitoring during spontaneously occurring breathholds, coupled with analytical measures derived from these signals $(4,11,13)$. Julu and others proposed a disturbance in cardiovascular and respiratory system integration, describing their findings as central autonomic dysfunction $(4,11,13)$. Further support for autonomic dysregulation comes from observations of decreased heart rate variability, longer corrected QT intervals, sinus bradycardia, gaseous abdominal distension, sweating, cool extremities (3,7,18-23), flushing and temperature dysregulation (M. Coenraads, personal communication).

Despite survival into adulthood, Kerr and colleagues $(24,25)$ reported that $20-26 \%$ of $\mathrm{RS}$ deaths are sudden and unexpected, and that the deaths occur primarily during wakefulness. QT prolongation and nonspecific ST changes in RS suggest cardiac causes for sudden death, though sudden death has been reported with normal QT intervals (26). Here we further characterize the autonomic phenotype of cardiorespiratory dysregulation in young girls with $M E C P 2$ mutationconfirmed RS, studied in their home environment. The intent was to characterize breath-to-breath irregularities and cardiorespiratory changes associated with breathholds, rather than a catalogue of breathing abnormalities $(4,13)$.

\section{METHODS}

Rett patients. Girls aged 2-7 y with clinical RS and a MECP2 mutation were recruited.

Control subjects. Healthy girls matched for age/ethnicity to girls with RS were recruited. Exclusion criteria included obstructive sleep apnea and any family history for three generations of RS, sudden infant death syndrome, congenital central hypoventilation syndrome, Hirschsprung disease, neural

\footnotetext{
Abbreviations: AMP, amplitude of respiratory inductance plethysmography sum; CV, coefficient of variation; $\mathbf{L F}$, low-frequency heart beat components; MECP2, gene encoding methyl-CpG-binding protein 2 on the X chromosome; RMS, root-mean-square amplitude of correlation; RS, Rett syndrome; $\mathbf{T}_{\mathbf{E}}$, expiratory time; $\mathbf{T}_{\mathbf{I}}$, inspiratory time; $\mathbf{T}_{\mathbf{I}} / \mathbf{T}_{\mathbf{T O T}}$, duty cycle; $\mathbf{T}_{\mathbf{T O T}}$, cycle length $\left(T_{I}+T_{E}\right)$
} 
crest tumors, familial dysautonomia, and apparent life-threatening events in infancy.

Consent process. The study was approved by the Rush University Medical Center Institutional Review Board. Consent and HIPAA forms were reviewed and signed by parents of study subjects.

Recording technology. Data were recorded in each subject's home using noninvasive ambulatory LifeShirt technology (VivoMetrics, Inc., Ventura, CA) to record breathing using a fabric zipper-front vest with two intrinsic inductance plethysmography bands at chest and abdomen, heart rate using three surface chest electrodes, and $\mathrm{Hb}$ saturation using a pulse oximeter. Participant data were recorded on a removable memory flashcard and coded to ensure participant anonymity and objectivity in data analysis.

Data collection protocol. Girls with RS and matched controls were instructed to wear the LifeShirt monitor continuously, for two consecutive hours on two consecutive mornings, and to watch singing videos while in the seated position. This instruction was included because a breathhold is typically demonstrated just before making voice to sing, and because girls with RS are typically seated at rest. Since one of the intents of the study was to compare the physiologic changes that accompany breathholds it was essential to assure such events occurred with regularity among control subjects.

Wave form computerized scoring. Inductance plethysmography waveforms (chest, abdomen, sum), ECG, Hb saturation, and pulse wave form were exported, then loaded into Igor Pro (WaveMetrics, Lake Oswego, OR) for analysis using custom-developed software. End-inspiration (shown as + ) and end-expiration (shown as $\times$ ) were detected through automated routines (Fig. 1) and data points were manually repositioned to insure proper breath detection. Individual breaths were classified as nonbreathhold breaths, breathholds, or contamination by artifact; breathholds were identified by wave form configuration (Fig. 2A). R waves were detected on ECG trace and verified; their timing was used to compute heart rate (HR), R-R interval and R-R irregularity. Movement artifact on the pulse oximetry channel was a consistent problem among RS, precluding analysis.

Data sampling algorithm. Study duration was $127 \pm 18$ and $118 \pm 13 \mathrm{~min}$ (mean $\pm \mathrm{SD}$ ) in RS and controls, respectively.

Cardiorespiratory variables included in analysis. Respiratory variables included: inspiratory time $\left(\mathrm{T}_{\mathrm{I}}\right)$, expiratory time $\left(\mathrm{T}_{\mathrm{E}}\right)$, cycle length $\left(\mathrm{T}_{\text {TOT }}=\mathrm{T}_{\mathrm{I}}\right.$ $+\mathrm{T}_{\mathrm{E}}$ ), duty cycle $\left(\mathrm{T}_{\mathrm{I}} / \mathrm{T}_{\mathrm{TOT}}\right), \mathrm{T}_{\mathrm{TOT}}$ irregularity, breathhold $\mathrm{T}_{\mathrm{TOT}}$ (start of one breathhold to start of next breathhold), breathhold $\mathrm{T}_{\text {TOT }}$ irregularity, inductance plethysmography amplitude sum (AMP) (Fig. 1), peak and mean inspiratory flow, and change in end-expiratory and end-inspiratory volumes. Heart beat variables included heart rate and R-R irregularity. Irregularity was defined for both respiratory and heartbeat variables as fractional change in $\mathrm{T}_{\mathrm{TOT}}$ (or R-R interval) from one cycle to the next: $\operatorname{Irreg}(n)=\left[\mathrm{T}_{\mathrm{TOT}}(n)-\right.$ $\left.\mathrm{T}_{\text {TOт }}(n-1)\right] / \mathrm{T}_{\text {Tот }}(n-1)$. Irregularity measures included $\mathrm{CV}$ to indicate overall variability and/or an irregularity score to indicate variability comparing consecutive cycles.

Wave form analysis specific to breathholds. Breaths were classified as being five or fewer breaths before or following a breathhold, or at least five breaths from a breathhold in either direction ("normal breaths") (Fig. 3A). R-R intervals were similarly grouped.

Cross-correlation analysis of breathing and heart rate. The relationship between breathing and heart rate was examined using cross-correlation applied to a 30-min section of stable waveforms. There were two distinct

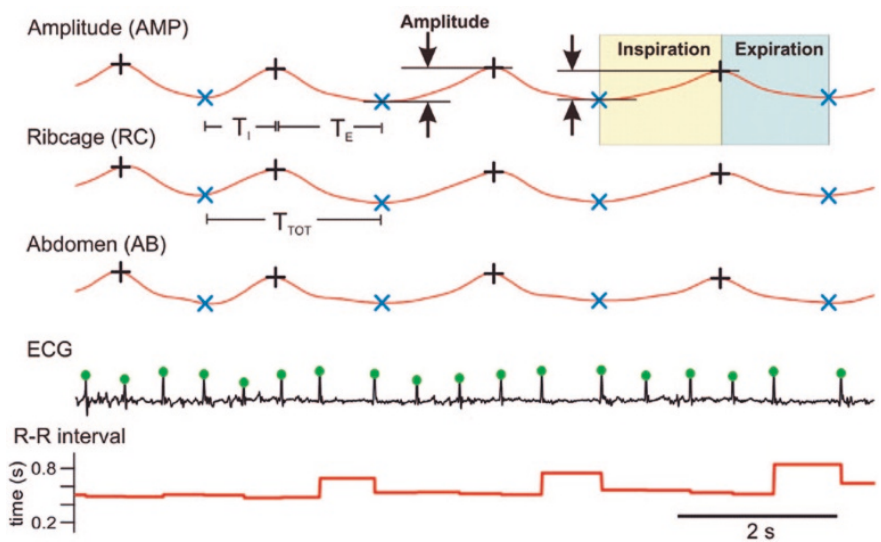

Figure 1. Inductance plethysmography waveforms [amplitude $(A M P)$, ribcage $(R C)$, and abdomen $(A B)]$ and ECG (R-R interval) from a 7-y-old girl with RS indicating end-inspiration and end-expiration, $\mathrm{T}_{\mathrm{I}}$ and $\mathrm{T}_{\mathrm{E}}$, as well as $\mathrm{R}$ wave peak.
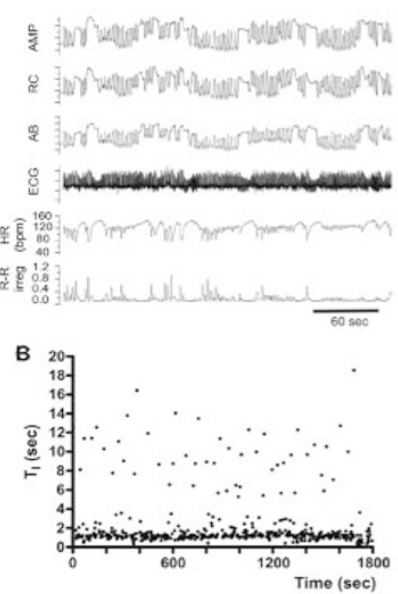

C
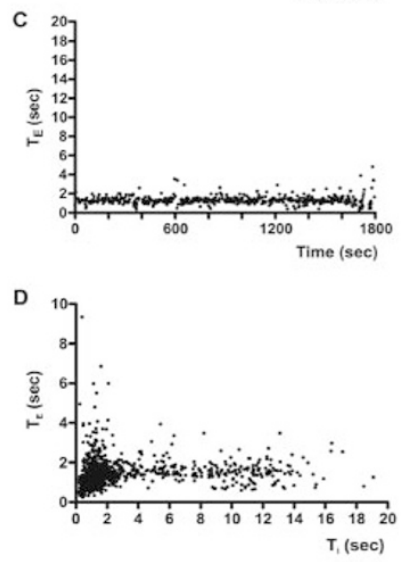

E

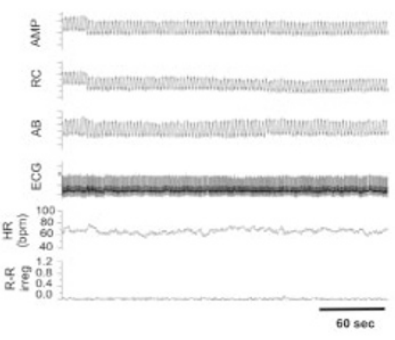

$\mathbf{F}$

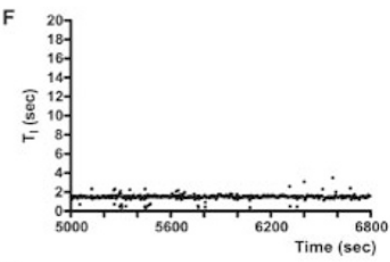

G

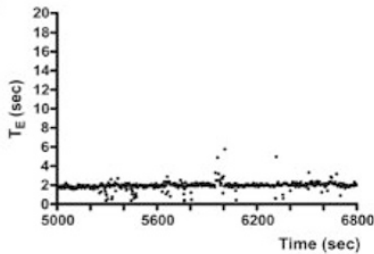

H

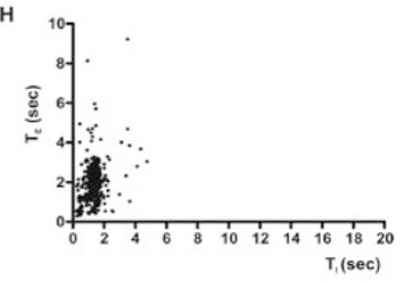

Figure 2. Breaths and breathholds in one 7-y-old girl with RS $(A-D)$ and her age-matched control $(E-H)$. Inductance plethysmography waveforms (AMP, $\mathrm{RC}, \mathrm{AB}), \mathrm{ECG}$, heart rate (HR), and R-R irregularity in RS $(A)$ and a control (E). $B, F$ : Sequential histograms of consecutive $\mathrm{T}_{\mathrm{I}}$ (ordinates, $B, F$ ) and $\mathrm{T}_{\mathrm{E}}$ values (ordinates, $C, G$ ) are plotted over time (abscissa). $D, H$ : Scatter plot of $\mathrm{T}_{\mathrm{E}}$ vs $\mathrm{T}_{\mathrm{I}}$.

components: the first corresponding to a series of peaks at intervals of $\mathrm{T}_{\mathrm{TOT}}$ with the largest peak at approximately zero lag, and the second corresponding to a broad peak with a maximum at 4-6 s lag. Because of overlap, we alternately filtered out one component and measured the strength of the other by applying perfect frequency-domain filters to the Fourier-transformed correlation, then transforming back into the time domain. To isolate the respiratory component, a bandpass filter was applied from $0.7 \times \mathrm{f}$ to $2.0 \times \mathrm{f}$, where $\mathrm{f}$ is respiratory frequency, measured from autocorrelation performed on AMP for the same $30 \mathrm{~min}$ section of recording. To isolate the broad peak (heart rate component), a bandpass filter was applied from $0.03 \mathrm{~Hz}(1 / 30 \mathrm{~s})$ to $0.7 \times \mathrm{f}$. The cutoff frequency of $0.7 \times \mathrm{f}$ was chosen to provide optimal separation while preserving the broad peak configuration. Similarly, the $0.03 \mathrm{~Hz}$ cutoff was chosen to preserve the shape of the broad peak while eliminating baseline shifts and other very low frequency (LF) components. After filtering, rootmean-square (RMS) amplitude of the correlation over the 20-s window centered on zero-lag (for both the $\mathrm{f}$ and LF heart beat components), and location and amplitude of the peak in the LF component were measured.

Statistical analysis. Data are presented as mean $\pm \mathrm{SD}$ or \pm SE. $t$ Test was used to compare mean differences between RS cases versus controls. Significance was applied to $p<0.05$.

\section{RESULTS}

Study subjects. Forty-seven girls with MECP2 mutationconfirmed RS and 47 matched controls were studied: 44 Caucasian, two biracial, and one multiracial child in each group. Mean ages (SD) were 4.7 y (1.3) and 4.8 y (1.3), respectively. 

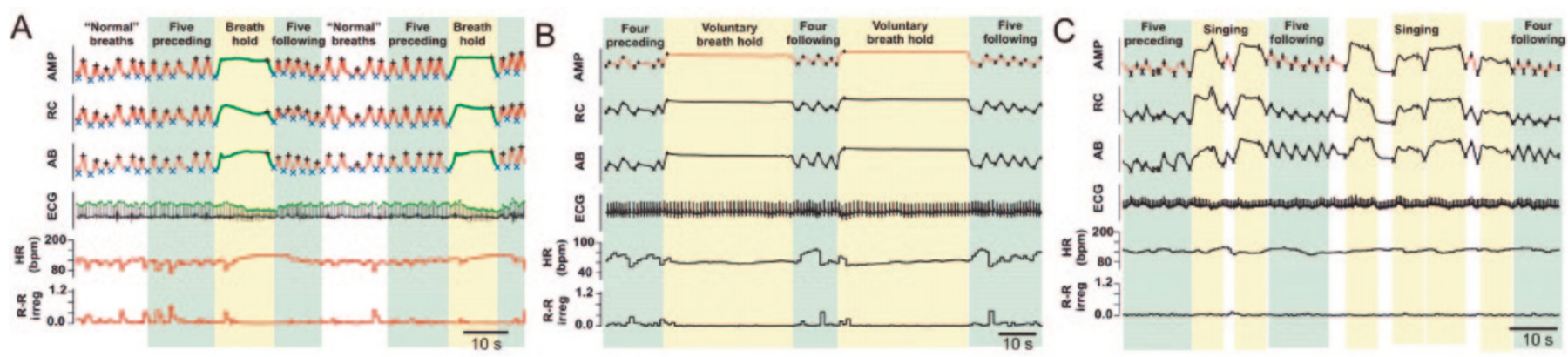

Figure 3. Characterization of spontaneous breathholds in one 7-y-old girl with RS $(A)$ and voluntary $(B)$ and pre-singing breathholds $(C)$ in two different 7 -y-old controls. Inductance plethysmography waveforms (AMP, RC, AB), ECG, HR, and R-R irregularity are shown for $A, B$, and $C$. Data categories: "normal" breaths, breathholds, five breaths preceding and following breathholds.

Qualitative data analysis: breathholds. RS patients exhibit spontaneous and frequent occurrence of breathholds (Fig. 2A), with rib cage, abdomen, and sum waveforms maintained in inspiratory phase with variable breathhold amplitude. Maintenance of inspiration at an amplitude similar to or exceeding the amplitude of preceding or following breaths suggests that this activity pattern is neither Valsalva nor central apnea. Rib cage and abdomen deflections in the same direction indicate that this activity pattern is not paradoxical breathing. However, study technology does not allow unambiguous discrimination between apneusis and breathholding (surface EMG would be required) and Valsalva maneuver (intrathoracic pressure measurements would be required). Thus, we simply use the term "breathholds." Plotting $\mathrm{T}_{\mathrm{I}}$ of consecutive individual breaths over time reveals frequent occurrence of prolonged $\mathrm{T}_{\mathrm{I}}$ values $(>4 \mathrm{~s})$ that reflect spontaneous breathholds (Fig. $2 B$ ). Prolonged $\mathrm{T}_{\mathrm{E}}$ values compatible with central apnea were absent in the sequential $\mathrm{T}_{\mathrm{E}}$ histogram (Fig. 2C). Likewise, plots of $T_{I}$ against $T_{E}$ reveal a large spread of $T_{I},(<20$ s), but not $\mathrm{T}_{\mathrm{E}}$ (Fig. 2D).

The representative control exhibits regular breathing without spontaneous breathholds (Fig. 2 E). Prolonged inspiratory (Fig. $2 F$ ) and expiratory durations (Fig. $2 G$ ) are absent in sequential $\mathrm{T}_{\mathrm{I}}$ (Fig. $2 F$ ) and $\mathrm{T}_{\mathrm{E}}$ histograms (Fig. $2 G$ ). Plotting $T_{I}$ against $T_{E}$ results in a larger spread of $T_{E}$ compared with $\mathrm{T}_{\mathrm{I}}$ (Fig. $2 H$ ), which is distinctly different from the child with RS.

Breathholds occurred frequently, but not regularly in RS. Inter-breathhold intervals could be short (Fig. $4 A$ ) or prolonged (Fig. 4B). The plot of 100 consecutive inter-breathhold intervals (IBI, Fig. 4C) illustrates the absence of obvious regularity in breathhold occurrence, but time between two consecutive breathholds tended to be longer (Fig. $4 C$ ) if the duration of the first breathhold was long (Fig. $4 D)\left(r^{2}=0.381\right.$; slope $p<0.0001$ ) (Fig. 4, $A$, and $B$ ). Intervals between consecutive brief breathholds were short (Fig. $4 A$ ), whereas a long IBI followed a longer breathhold (Fig. $4 B$ ).

Heart rate response in $R S$. Figures $2 A, 3 A$, and $4 A$ and $B$ demonstrate a pronounced increase in heart rate with each breathhold (16.1 \pm 9.7\% in the representative girl in Figure 4, $p<0.00001)$. Although the percentage heart rate increase per breathhold was variable (Fig. $4 E$ ), heart rate measured at exhalation onset tended to be higher after long duration breathholds when compared with shorter duration breathholds (Fig. 4F).

Comparison between breathholds in RS and voluntary and pre-singing breathholds in controls. We qualitatively compared breathholds in a child with RS (Fig. 3A) with breathholds voluntarily produced in a control (Fig. 3B). Voluntary breathholds (Fig. $3 B$ ) were longer than spontaneous RS breathholds (Fig. 3A), but respiration tracings were otherwise not different. However, it was neither practical nor safe to instruct 2-7 y olds to breathhold repeatedly in the home without clinical supervision. A practical alternative to voluntary breathholds was singing along to a familiar videotape (Fig. 3C). During a pre-singing breathhold, diaphragmatic activity was maintained in a phase commonly referred to as postinspiration (27). Like breathholds in RS (Fig. 3A), respiratory activity for the pre-singing control breathhold was maintained in inspiration in the sum, rib cage, and abdomen channels (Fig. 3C) and the amplitude of these breathholds could exceed the amplitude of preceding nonbreathhold breaths. Despite similarities in the respiratory traces, available technology does not allow us to determine whether voluntary breathholds or the breathhold before singing in controls have the same neuronal basis as breathholds observed in RS, i.e. apneusis versus breathholds.

The heart rate response to the RS breathhold was qualitatively very different from the response to a voluntary control breathhold (Fig. 3). In RS, the heart rate increased during the breathhold (Fig. 3A) but remained unchanged in the control (Fig. 3B). Heart rate change was not significant in the control voluntary breathhold $(6.2 \pm 12.85 \%, p=0.58)$, or the presinging breathhold $(-4.4 \pm 26.6 \%)$ (Fig. $3 C)$; though the latter sometimes produced brief IBI (Fig. 5A), they did not occur regularly (Fig. 5B). In contrast to RS (Fig. $4 D$ ), the IBI in the control did not depend on breathhold duration (Fig. $5 \mathrm{C}$ ), heart rate was not altered in a regular manner by consecutive breathholds (Fig. 5D), and there was no dependency between breathhold duration and heart rate (Fig. 5E).

Quantitative data analysis: cardiorespiratory timing parameters. To quantify differences in breathing behavior, data were separated into four categories: 1) "normal" breaths (Table 1, supplemental material online); 2) breathholds (Table 2, supplemental material online); 3) 5 breaths preceding a breathhold (Table 3, supplemental material online); and 
A

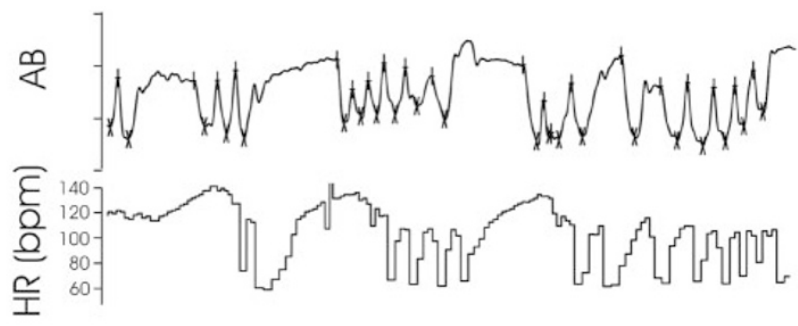

B

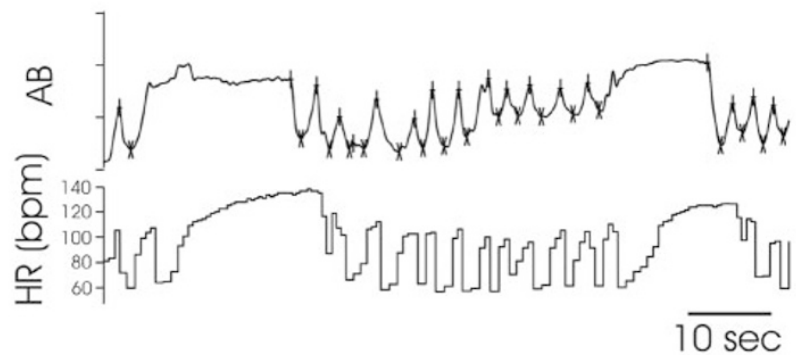

C

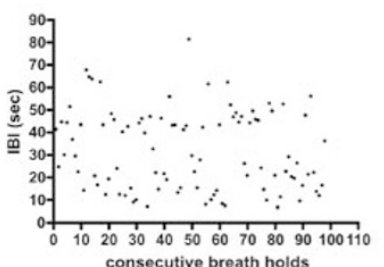

E

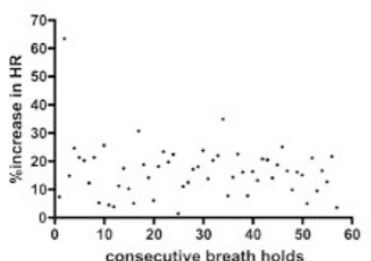

D

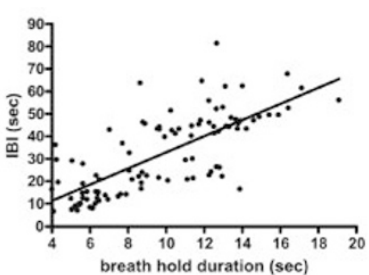

$\mathrm{F}$

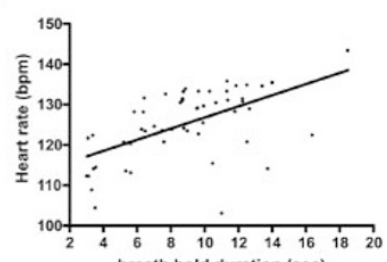

Figure 4. Breathholds in RS. $(A, B)$ Inductance plethysmography waveforms and HR are shown. (C) Sequential histogram plots IBI (ordinate) between 100 consecutive breathholds (abscissa). (D) Histogram plots breathhold duration (abscissa) against interval to subsequent breathhold (IBI, ordinate) $(p<$ $\left.0.00001, r^{2}=0.65\right)$. (E) Sequential histogram plots percent HR increases (ordinate) for 60 consecutive breathholds (abscissa). $(F)$ Histogram plots heart rate responses to breathholds (ordinate) against duration (abscissa) $(p<$ $0.0001, r^{2}=0.32$ ).

4) 5 breaths following a breathhold (Table 4, supplemental material online). Data expressed as percent change comparing RS versus controls are provided in Results; raw data are provided in Tables 1-4 (supplemental material online).

"Normal" breaths. $\mathrm{T}_{\mathrm{TOT}}$ was significantly shorter in RS when compared with matched controls $(-18.89 \% ; p<$ $0.00001)$ and cycles were more irregular (CV: $62.54 \%, p<$ 0.0001 ; irregularity score: $68.93 \%, p<0.00001$ ), demonstrating consistency with Figure $2, B$ and $F$. The $\mathrm{T}_{\text {TOT }}$ decrease was due to decreased $\mathrm{T}_{\mathrm{I}}(-10.19 \% ; p<0.007)$ and $\mathrm{T}_{\mathrm{E}}$ $(-25.16 \% ; p<0.00001)$, consistent with Figure $2, C$ and $D$ [CV: $55.4 \%\left(\mathrm{~T}_{\mathrm{I}}\right), 56.13 \%\left(\mathrm{~T}_{\mathrm{E}}\right)$, both $\left.p<0.00001\right]$.

Time to peak AMP was not different, but mean and peak $\mathrm{AMP} / \mathrm{T}_{\mathrm{I}}$ were enhanced in $\mathrm{RS}(17.94 \%, 17.51 \%$, both $p<$ $0.00001)$, as was associated irregularity (CV: $35.27 \%, 29.4 \%$, $p<0.00001)$.

A
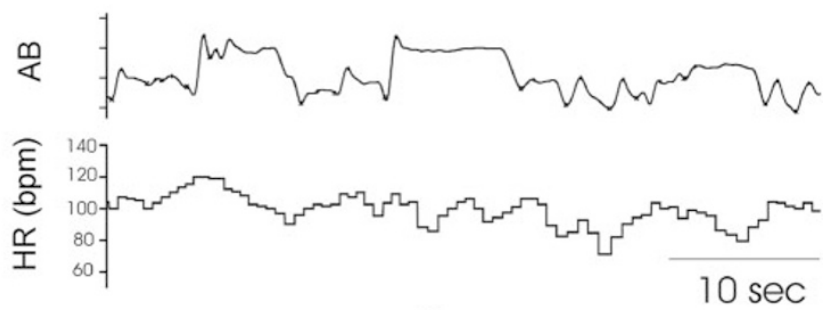

B

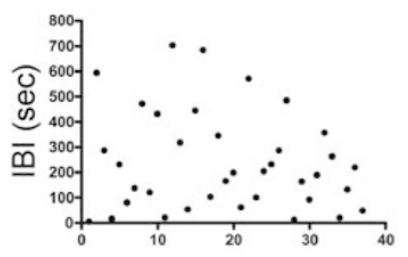

Consecutive breathholds

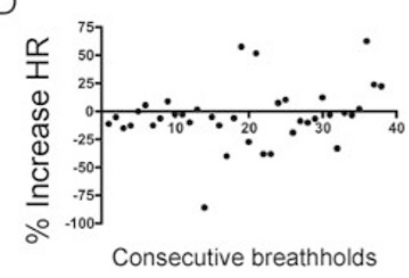

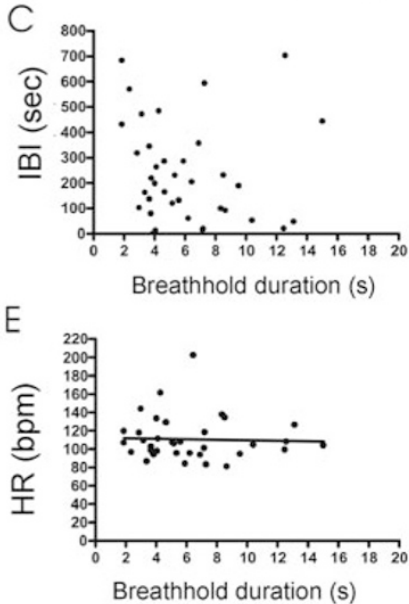

Breathhold duration (s)
Figure 5. "Breathholds" in controls. (A) Inductance plethysmography wave form (AB), and HR are shown. (B) Sequential histogram plots IBI (ordinate) between 39 consecutive breathholds (abscissa) in a 7-y-old control. (C) Histogram plots breathhold duration (abscissa) against intervals to subsequent breathholds (IBI, ordinate). (D) Sequential histogram plots percent HR changes (ordinate) for 39 consecutive breathholds (abscissa). (E) Histogram plots heart rate responses to breathholds (ordinate) against duration (abscissa).

Heart rate was increased in RS (mean R-R interval: $-9.41 \%, p<0.0001$ ) and was more regular (irregularity score: $-29.17 \%, p<0.04)$.

Breathholds. Inter-breathhold intervals and $\mathrm{T}_{\mathrm{TOT}}$ were not significantly different between RS and controls, allowing us to match on average frequency and duration of breathholds. However, timing of breathholds differed: $\mathrm{T}_{\mathrm{I}}: 21.93 \%(p<$ $0.002), \mathrm{T}_{\mathrm{E}}:-14.85 \%(p<0.018) . \mathrm{T}_{\mathrm{E}}$ was more irregular (CV: $15.25 \%, p<0.0025)$ in RS versus controls.

Time to peak AMP of breathholds was shorter $(-8.56 \pm$ $13.84 \%, p<0.001)$, peak AMP/T 1 I $17.54 \%, p<0.01)$, and associated variability were decreased $(\mathrm{CV}:-10.98 \%, p<$ $0.01)$.

During breathholds, mean R-R interval decreased in RS $(-4.28 \%, p<0.04)$, but not irregularity score or CV.

Breaths preceding and following breathholds. $\mathrm{T}_{\mathrm{TOT}}$ for the five breaths before and after breathholds was shorter in RS versus controls $(-12.16 \%, p<0.009 ;-12.7 \%, p<$ 0.006 , respectively) and more irregular (CV before: $32.79 \%, p$ $<0.0001$; after: $32.25 \%, p<0.00001$; irregularity score before: $44.12 \%, p<0.00006$; after: $38.54 \%, p<0.00005$ ). The five breaths before and after breathholds demonstrated decreased $\mathrm{T}_{\mathrm{E}}$ (before: $-19.14 \%, p<0.00005$; after: $-20.46 \%, p<0.00002)$. Both $\mathrm{T}_{\mathrm{I}}$ and $\mathrm{T}_{\mathrm{E}}$ were more irregular $\left(\mathrm{CV}\right.$ before: $\mathrm{T}_{\mathrm{I}}: 27.67 \%, p<0.001$; after: $25.10 \%, p<$ 
0.0002; before: $\mathrm{T}_{\mathrm{E}}: 26.22 \%, p<0.0004$; after: $27.25 \%, p<$ $0.00001)$.

Time to peak AMP did not differ, but mean and peak $\mathrm{AMP} / \mathrm{T}_{\mathrm{I}}$ of the five breaths before a breathhold increased (19.3\%, $p<0.007$ in RS; $18.04 \%, p<0.013$ in controls).

Heart rate was increased among RS (mean R-R interval: $-7.32 \%, p<0.0004$ for five breaths before a breathhold, $-7.22 \%, p<0.0005$ for five breaths after a breathhold).

Cross-correlation analyses. Cross-correlation methods evaluated differences in cardiorespiratory interactions. In a representative girl with RS each breathhold (Fig. 6A, green) was associated with an initial decrease (Fig. 6A, "zero lag decrease," light green arrow) and a subsequent increase in heart rate (Fig. 6A, "delayed increase," dark green). During each "normal" breath there was a zero-lag increase in heart rate (Fig. 6 A, "zero lag increase," red arrows). Two different responses to breathholds and "normal" breaths were reflected in cross-correlation analyses between AMP and heart rate waveforms (Fig. 6B). The upper graph showing the unfiltered correlation between heart rate and respiratory activity confirms a peak at zero lag indicating an instantaneous heart rate increase during each respiratory cycle and a second peak
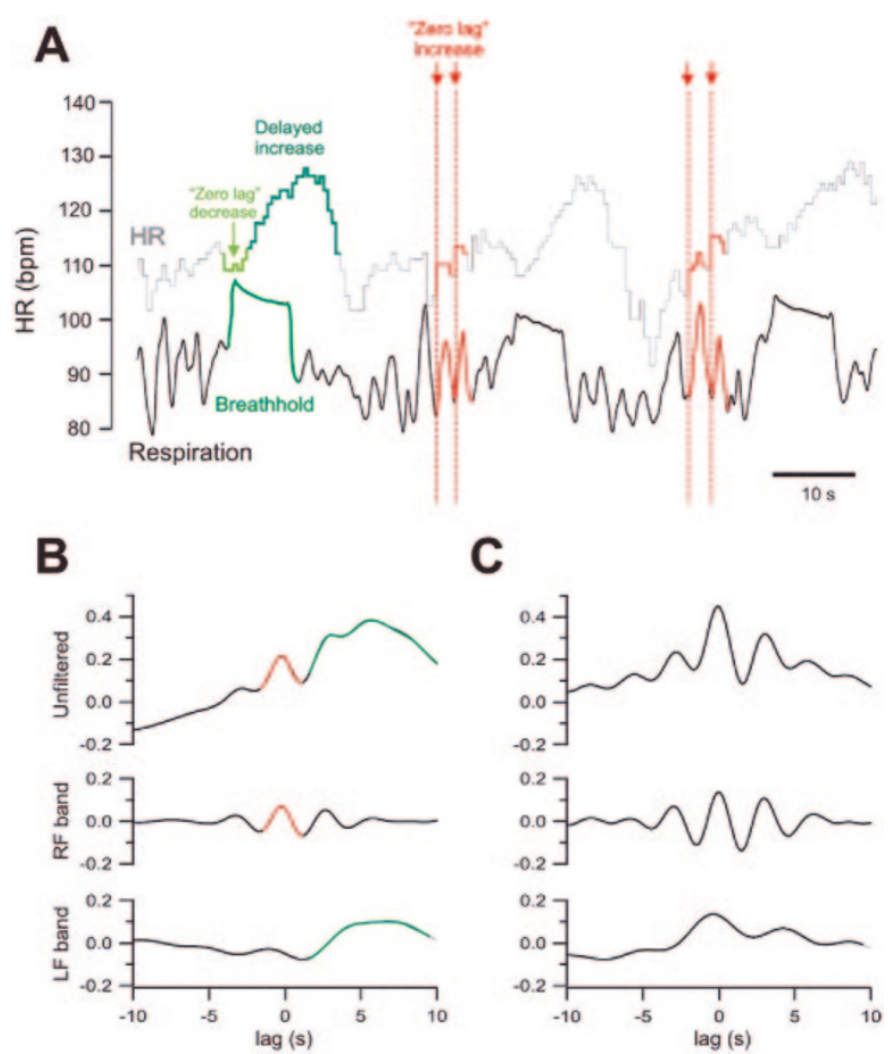

Figure 6. Cross-correlation analysis in one 7-y-old with RS and her matched control. (A) HR (upper trace, light gray) and respiratory inductance channel are shown $(\mathrm{AMP}=$ unitless, lower trace, black). One breathhold (green) and four representative "normal" breaths (red) are marked to highlight differential heart rate responses. During breathholds an initial decrease ("zero-lag decrease") is followed by a delayed heart rate increase ("delayed increase"). During "normal" breaths HR increases immediately ("zero-lag increase"). (B) Correlation and filtering for the example shown in $A$ (RS). Top panel = unfiltered; middle panel $=$ respiratory frequency $(\mathrm{RF})$ band; bottom panel $=$ low-frequency (LF) heart rate band. $(C)$ Example from a matched control with peaks at about $5 \mathrm{~s}$ and zero lag in LF component. reflecting the delayed heart rate increase (described above). Comparison with a matched control (Fig. 6C) suggests that peak correlation at zero lag in RS (Fig. 6B, upper graph) was attenuated, which becomes more evident in the respiratory domain after wave form filtering (Fig. 6, $B$ and $C$, middle graphs). The delayed heart rate response was enhanced in RS (Fig. 6C, upper graph), and is consistent with heart rate traces in Figures $2 A, 3 A$, and $4 A$ and $B$ ). The LF band (Fig. 6B, lower graph) illustrates the heart rate response to breathholds: an initial decrease in correlation between heart rate and respiration during zero lag and a broad increased correlation over a period of 3-8 s in RS (Fig. 6B, lower graph), but not in the control (Fig. 6C, lower graph).

Cross-correlation analyses performed for all girls with RS and their matched controls confirmed these observations. Correlation analysis between respiration and heart rate was measured at zero lag for all breaths and related heart rates and provided as RMS values (Fig. 7, $A$ and $B$ ). RMS amplitude for RS was significantly decreased at zero lag (Fig. 7A). The heart rate low frequency band to characterize the response to respiratory activity peaked at approximately $4 \mathrm{~s} \mathrm{(Fig.} 7 B$ ), and did not differ in RS versus controls. Peak amplitude of heart rate correlation of at least one second lag revealed significantly increased amplitude in the heart rate LF band correlation in RS (Fig. 7C).

\section{DISCUSSION}

Previous studies aimed at categorizing various forms of breathing disturbances in RS (such as hyperventilation Valsalva maneuver, apneas, apneusis, and breathholds). In the present study, every consecutive breath and heart beat of a large cohort of 47 young girls with MECP2 mutationconfirmed RS and 47 age-, gender-, and ethnicity-matched controls were evaluated in a cycle-by-cycle manner in their home environment during daytime wakefulness. This approach revealed three previously unreported observations. Even when breathing is apparently normal in RS, it was 1) more irregular than normal breathing in controls, 2) mean inspiratory flow was increased, and 3) breathing frequency was significantly higher, primarily due to a decrease in expiratory duration. With respect to heart beat regulation, we observed: 1) R-R interval was shorter in RS, 2) normal breathing and heart rate variability had a decreased correlation, and 3) the heart rate response to breathholds was increased in RS versus controls. While controls showed a decreased heart rate during breathholding, the heart rate was increased in RS. It must be emphasized that, for obvious reasons, it is not possible to identify a "perfect" control behavior to match the "pathologic" breathholds commonly observed in RS. We thus opted to provoke repeated "breathholds" in controls by encouraging them to sing, which may have different mechanisms for inducing heart rate changes. The heart rate response of RS has been previously reported by Julu et al. $(4,11,13)$ and was attributed to be comparable to the response to a Valsalva maneuver. However, without further measurements, including intrathoracic pressure, EMG, and blood pressure, which were not assessed in the present study, 

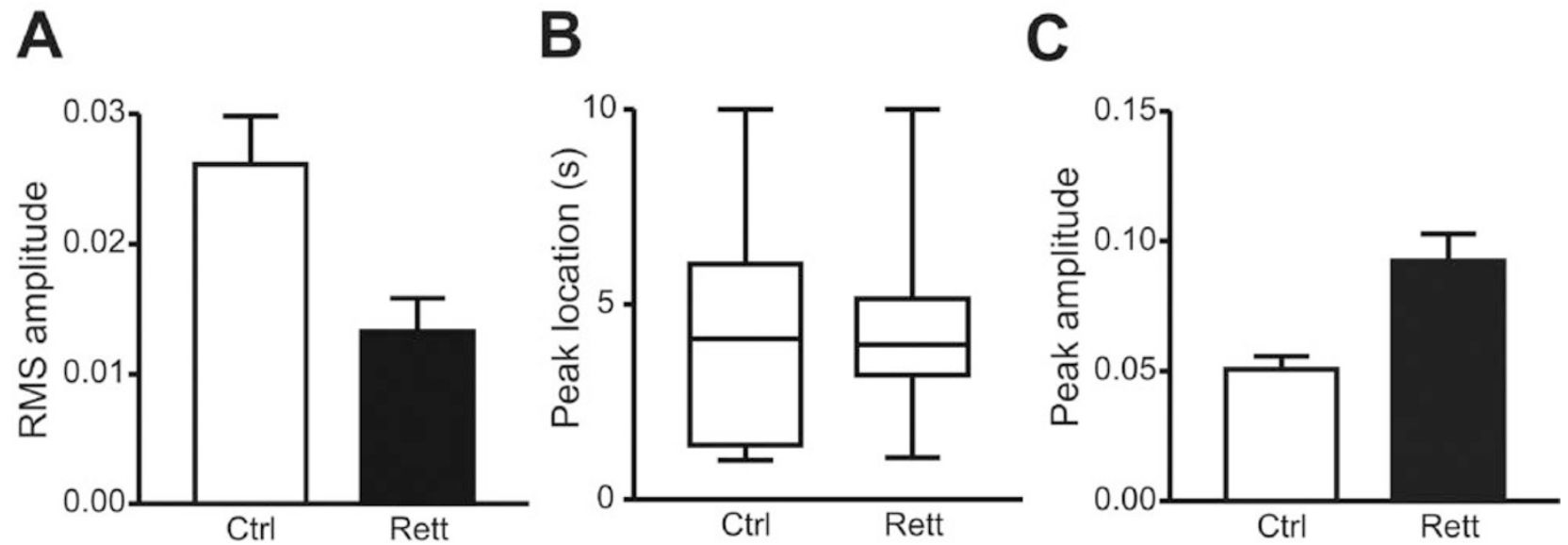

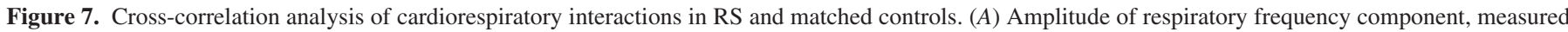

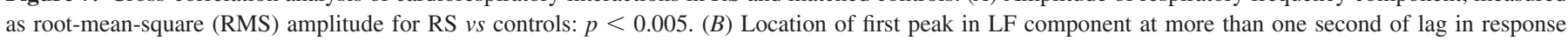

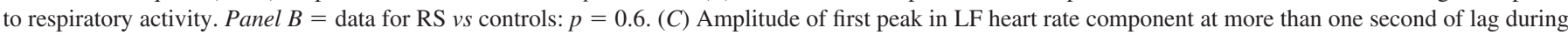
breathholds. Panel $C=$ data for RS vs controls: $p<0.006$.

an unambiguous identification of these breathholds is not possible. Our interpretation of the waveforms is that girls with RS demonstrate the breathhold during inspiration (in contrast to the Valsalva expiratory behavior).

Prior publications have relied on conventional in-hospital physiologic recordings using traditional scoring methods for measuring apnea, bradycardia, and $\mathrm{Hb}$ desaturation. These studies focused on disparate patterns of breathing, typically referring to breathholds as apnea or Valsalva maneuvers, and mostly with focus on what induces the breathhold pattern (6-17). Published studies report a varying number of subjects $(2-47$, median $=18)$, a broad age range at study $(1-32 \mathrm{y})$, typically unmatched and not necessarily healthy controls, and varying terms to describe the waveforms recorded. In contrast, our study includes a large number of girls, all with $M E C P 2$ mutation-confirmed RS $(n=47)$, in a finite age range (ages 2-7 y), with matched controls having no symptoms/family history of autonomic disease. Moreover, no existing study used nonlinear analysis.

Our cross-correlation analysis revealed distinct differences in heart rate responses to breathholds among RS versus controls. During "normal" breaths, the heart rate response was instantaneous in RS and controls, but during breathholds, girls with RS had an initial subtle decrement in heart rate followed by a delayed, exaggerated heart rate response. Considering the frequent reoccurrence of breathholds, with associated overshoot and lag in heart rate response, one could hypothesize that cardiorespiratory homeostasis would be threatened in the most severely affected girls thereby increasing their risk of sudden death (25). The known decreased heart rate variability and prolonged $\mathrm{QT}_{\mathrm{c}}(19,20,23)$, together with these repeated breathholds, could potentially explain the incidence of sudden death during wakefulness in RS. Some otherwise healthy individuals with long QT syndrome manifest symptoms when swimming $(28,29)$, an activity associated with repetitive breathholds, though the specific arrhythmogenic influence of swimming is unknown. It is reasonable to consider that RS is a model for repeated breathholds that, like swimming, creates a challenge eliciting aberrant dynamics resulting in sudden deaths in non-Rett children with long QT syndrome. Even in the absence of long QT syndrome or other channelopathies (30), one might hypothesize that the cardiac rhythm channel milieu may be compromised in RS with repeated breathholding and cardiorespiratory disassociation.

As already mentioned, our results are associated with several caveats: these studies were (by design) completed in the home environment and not supervised by medical personnel. The technique we used to create "breathholds" among controls is clearly not identical physiologically to the breathholds spontaneously occurring in RS. Finally, our data collected in young girls cannot be extrapolated to older girls with RS.

The disturbed heart rate response and irregular breathing are presumably the result of an aberrant medullary neuronal network. Studies in a mouse model for RS indicate that the irregular respiratory rhythm is explained by disturbed medullary levels of norepinephrine and serotonin (31). These animal studies are consistent with disturbances in serotonin transporter as described in human patients with RS (32). Further elucidation of the mechanisms underlying cardiorespiratory dysregulation and their neurochemical basis will ideally lead to intervention strategies to modify the cardiorespiratory phenotype in RS.

In summary, our study indicates that girls with RS demonstrate faster, deeper, and more erratic breathing as well as heart rate dysregulation during wakefulness when compared with matched controls. These results also reveal a profound dysregulation of the heart rate response to breathholds, and breaths preceding breathholds in young girls with RS. Taken together, these findings may offer insight into potential intervention strategies and into understanding mechanisms responsible for sudden death in Rett Syndrome.

Acknowledgments. The authors thank VivoMetrics, Inc. for providing the LifeShirt vest technology. We also thank the RS Research Foundation for grant support and Monica Coenraads, in particular, who made subject recruitment successful. We thank the girls and their families who generously participated in this study, the families who shared the technology 
shipment expenses, and Henner Koch and Nicolo Ramirez for their assistance.

\section{REFERENCES}

1. Axelrod FB, Chelimsky GG, Weese-Mayer DE 2006 Pediatric autonomic disorders: state of the art review article. Pediatrics 118:309-321

2. [No authors listed] 1988 Diagnostic criteria for Rett syndrome. The Rett Syndrome Diagnostic Criteria Work Group. Ann Neurol 23:425-428

3. Kerr AM, Nomura Y, Armstrong D, Anvret M, Belichenko PV, Budden S, Cass H, Christodoulou J, Clarke A, Ellaway C, d'Esposito M, Francke U, Hulten M, Julu P, Leonard H, Naidu S, Schanen C, Webb T, Engerstrom IW, Yamashita Y, Segawa M 2001 Guidelines for reporting clinical features in cases with $M E C P 2$ mutations. Brain Dev 23:208-211

4. Julu PO, Engerstrom IW 2005 Assessment of the maturity-related brainstem functions reveals the heterogeneous phenotypes and facilitates clinical management of Rett syndrome. Brain Dev 27:S43-S53

5. Amir RE, Van den Veyver IB, Wan M, Tran CQ, Francke U, Zoghbi HY 1999 Rett syndrome is caused by mutations in X-linked $M E C P 2$, encoding methyl-CpGbinding protein 2. Nat Genet 23:185-188

6. Cirignotta F, Lugaresi E, Montagna P 1986 Breathing impairment in Rett syndrome. Am J Med Genet Suppl 1:167-173

7. Southall DP, Kerr AM, Tirosh E, Amos P, Lang MH, Stephenson JB 1988 Hyperventilation in the awake state: potentially treatable component of Rett syndrome. Arch Dis Child 63:1039-1048

8. Kerr AM 1992 A review of the respiratory disorder in the Rett syndrome. Brain Dev 14:S43-S45

9. Elian M, Rudolf NM 1991 EEG and respiration in Rett syndrome. Acta Neurol Scand 83:123-128

10. Woodyatt GC, Murdoch BE 1996 The effect of the presentation of visual and auditory stimuli on the breathing patterns of two girls with Rett syndrome. J Intellect Disabil Res 40:252-259

11. Julu PO, Kerr AM, Hansen S, Apartopoulos F, Jamal GA 1997 Functional evidence of brain stem immaturity in Rett syndrome. Eur Child Adolesc Psychiatry 6:47-54

12. Kerr AM, Julu PO 1999 Recent insights into hyperventilation from the study of Rett syndrome. Arch Dis Child 80:384-387

13. Julu PO, Kerr AM, Apartopoulos F, Al-Rawas S, Engerström IW, Engerström L, Jamal GA, Hansen S 2001 Characterization of breathing and associated central autonomic dysfunction in the Rett disorder. Arch Dis Child 85:29-37

14. Lugaresi E, Cirignotta F, Montagna P 1985 Abnormal breathing in the Rett syndrome. Brain Dev 7:329-333

15. Glaze DG, Frost JD Jr, Zoghbi HY, Percy AK 1987 Rett's syndrome: characterization of respiratory patterns and sleep. Ann Neurol 21:377-382
16. Schlüter B, Aguigah G, Buschatz D, Trowitzsch E, Aksu F 1995 Polysomnographic recordings of respiratory disturbances in Rett syndrome. J Sleep Res 4:203-207

17. Marcus CL, Carroll JL, McColley SA, Loughlin GM, Curtis S, Pyzik P, Naidu S 1994 Polysomnographic characteristics of patients with Rett syndrome. J Pediatr $125: 218-224$

18. Nomura Y, Kimura K, Arai H, Segawa M 1997 Involvement of the autonomic nervous system in the pathophysiology of Rett syndrome. Eur Child Adolesc Psychiatry 6:42-45

19. Guideri F, Acampa M, DiPerri T, Zappella M, Hayek Y 2001 Progressive cardiac dysautonomia observed in patients affected by classic Rett Syndrome and not in the preserved speech variant. J Child Neurol 16:370-373

20. Sekul EA, Moak JP, Schultz RJ, Glaze DG, Dunn JK, Percy AK 1994 Electrocardiographic findings in Rett syndrome: an explanation for sudden death? J Pediatr 125:80-82

21. Ellaway CJ, Sholler G, Leonard H, Christodoulou J 1999 Prolonged QT interval in Rett syndrome. Arch Dis Child 80:470-472

22. Madan N, Levine M, Pourmoghadam K, Sokoloski M 2004 Severe sinus bradycardia in a patient with Rett syndrome: a new cause for a pause? Pediatr Cardiol 25:53-55

23. Guideri F, Acampa M, Hayek G, Zappella M, DiPerri T 1999 Reduced heart rate variability in patients affected with Rett syndrome: a possible explanation for sudden death. Neuropediatrics 30:146-148

24. Kerr AM, Armstrong DD, Prescott RJ, Doyle D, Kearney DL 1997 Rett syndrome: analysis of deaths in the British survey. Eur Child Adolesc Psychiatry 6:71-74

25. Kerr AM, Prescott RJ 2005 Predictive value of the early clinical signs in Rett disorder. Brain Dev 27:S20-S24

26. Dearlove OR, Walker RW 1996 Anaesthesia for Rett syndrome. Paediatr Anaesth 6:155-158

27. Richter DW 1982 Generation and maintenance of the respiratory rhythm. J Exp Bio 100:93-107

28. Ackerman MJ, Porter CJ 1998 Identification of a family with inherited long QT syndrome after a pediatric near-drowning. Pediatrics 101:306-308

29. Ackerman MJ, Tester DJ, Porter CJ 1999 Swimming, a gene-specific arrhythmogenic trigger for inherited long QT syndrome. Mayo Clin Proc 74:1088-1094

30. Ackerman MJ 2005 Cardiac causes of sudden unexpected death in children and their relationship to seizures and syncope: genetic testing for cardiac electropathies. Semin Pediatr Neurol 12:52-58

31. Viemari JC, Roux JC, Tryba AK, Saywell V, Burnet H, Pena F, Zanella S, Bevengut M, Barthelemy-Requin M, Herzing LB, Moncla A, Mancini J, Ramirez JM, Villard L, Hilaire G 2005 MECP2 deficiency disrupts norepinephrine and respiratory systems in mice. J Neurosci 25:11521-11530

32. Paterson DS, Thompson EG, Belliveau RA, Antalffy BA, Trachtenberg FL, Armstrong DD, Kinney HC 2005 Serotonin transporter abnormality in the dorsal moto nucleus of the vagus in Rett syndrome: potential implications for clinical autonomic dysfunction. J Neuropathol Exp Neurol 64:1018-1027 
Table 1. Raw data from 47 Rett cases and 47 matched controls for "normal" breaths

\begin{tabular}{|c|c|c|c|}
\hline Variable & Measures & Rett cases & Controls \\
\hline \multirow{3}{*}{$\mathrm{T}_{\text {TOT (s) }}$} & Mean & $2.043 \pm 0.41$ & $2.52 \pm 0.44$ \\
\hline & $\mathrm{CV}$ & $0.37 \pm 0.09$ & $0.23 \pm 0.06$ \\
\hline & Irregularity & $0.35 \pm 0.13$ & $0.21 \pm 0.08$ \\
\hline \multirow{2}{*}{$\mathrm{T}_{\mathrm{I}(\mathrm{s})}$} & Mean & $0.948 \pm 0.166$ & $1.055 \pm 0.16$ \\
\hline & $\mathrm{CV}$ & $0.480 \pm 0.127$ & $0.309 \pm 0.09$ \\
\hline \multirow[t]{2}{*}{$\mathrm{T}_{\mathrm{E}(\mathrm{s})}$} & Mean & $1.095 \pm 0.283$ & $1.463 \pm 0.29$ \\
\hline & $\mathrm{CV}$ & $0.47 \pm 0.12$ & $0.30 \pm 0.08$ \\
\hline \multirow[t]{2}{*}{$\mathrm{T}_{\mathrm{I} / \mathrm{TOT}}$} & Mean & $0.47 \pm 0.04$ & $0.43 \pm 0.02$ \\
\hline & $\mathrm{SD}$ & $0.12 \pm 0.03$ & $0.09 \pm 0.02$ \\
\hline \multirow[t]{2}{*}{ Amplitude* } & Mean & $=1$ & $=1$ \\
\hline & $\mathrm{CV}$ & $0.08 \pm 0.03$ & $0.07 \pm 0.03$ \\
\hline \multirow[t]{2}{*}{ Mean $\mathrm{AMP} / \mathrm{T}_{\mathrm{I}}$} & Mean & $1.22 \pm 0.21$ & $1.03 \pm 0.14$ \\
\hline & $\mathrm{CV}$ & $0.58 \pm 0.13$ & $0.43 \pm 0.13$ \\
\hline \multirow[t]{2}{*}{ Peak AMP/T ${ }_{I}$} & Mean & $2.05 \pm 0.28$ & $1.74 \pm 0.26$ \\
\hline & $\mathrm{CV}$ & $0.56 \pm 0.12$ & $0.43 \pm 0.13$ \\
\hline \multirow[t]{3}{*}{$\mathrm{R}-\mathrm{R}$ interval (s) } & Mean & $0.52 \pm 0.06$ & $0.58 \pm 0.06$ \\
\hline & $\mathrm{CV}$ & $0.10 \pm 0.04$ & $0.10 \pm 0.03$ \\
\hline & Irregularity & $0.03 \pm 0.03$ & $0.05 \pm 0.02$ \\
\hline
\end{tabular}

Values expressed as $\pm \mathrm{SD}$.

* Amplitude $($ AMP $)=$ respiratory inductance plethysmography waveform sum signal; values normalized to 1 , equivalent to $100 \%$ of baseline.
Table 3. Raw data from 47 Rett cases and 47 matched controls for the last five breaths before a breathhold

\begin{tabular}{llcc}
\hline \multicolumn{1}{c}{ Variable } & Measures & Rett cases & Controls \\
$\mathrm{T}_{\mathrm{TOT}(\mathrm{s})}$ & Mean & $2.19 \pm 0.48$ & $2.49 \pm 0.43$ \\
& $\mathrm{CV}$ & $0.43 \pm 0.13$ & $0.32 \pm 0.08$ \\
& Irregularity & $0.44 \pm 0.15$ & $0.30 \pm 0.09$ \\
$\mathrm{~T}_{\mathrm{I}(\mathrm{s})}$ & Mean & $1.05 \pm 0.27$ & $1.09 \pm 0.23$ \\
$\mathrm{~T}_{\mathrm{E}(\mathrm{s})}$ & $\mathrm{CV}$ & $0.58 \pm 0.20$ & $0.45 \pm 0.12$ \\
& Mean & $1.14 \pm 0.27$ & $1.40 \pm 0.24$ \\
$\mathrm{~T}_{\mathrm{I} / \mathrm{T}} \mathrm{TOT}$ & CV & $0.54 \pm 0.12$ & $0.43 \pm 0.08$ \\
& Mean & $0.48 \pm 0.04$ & $0.44 \pm 0.03$ \\
Amplitude* & SD & $0.14 \pm 0.02$ & $0.12 \pm 0.02$ \\
& Mean & $1.29 \pm 0.63$ & $1.15 \pm 0.14$ \\
Mean AMP/T & CV & $0.10 \pm 0.05$ & $0.09 \pm 0.04$ \\
& Mean & $1.44 \pm 0.49$ & $1.21 \pm 0.19$ \\
Peak AMP/T & CV & $0.61 \pm 0.12$ & $0.58 \pm 0.13$ \\
& Mean & $2.50 \pm 0.90$ & $2.12 \pm 0.35$ \\
R-R interval (s) & CV & $0.58 \pm 0.12$ & $0.59 \pm 0.15$ \\
& Mean & $0.52 \pm 0.05$ & $0.56 \pm 0.05$ \\
& CV & $0.11 \pm 0.04$ & $0.11 \pm 0.03$ \\
& Irregularity & $0.04 \pm 0.03$ & $0.04 \pm 0.02$ \\
\hline
\end{tabular}

Values expressed as $\pm \mathrm{SD}$.

* Amplitude $(\mathrm{AMP})^{*}=$ respiratory inductance plethysmography waveform sum signal.
Table 2. Raw data from 47 Rett cases and 47 matched controls for breathholds

\begin{tabular}{llcc}
\hline \multicolumn{1}{c}{ Variable } & Measures & Rett cases & Controls \\
$\mathrm{T}_{\text {TOT for breatholds (s) }}$ & Mean & $33.5 \pm 26.2$ & $45.7 \pm 35.9$ \\
& CV & $1.34 \pm 0.74$ & $1.37 \pm 0.33$ \\
& Irregularity & $2.03 \pm 1.72$ & $2.53 \pm 1.27$ \\
$\mathrm{~T}_{\mathrm{TOT}(\mathrm{s})}$ & Mean & $5.94 \pm 1.62$ & $5.65 \pm 0.88$ \\
& CV & $0.42 \pm 0.11$ & $0.38 \pm 0.09$ \\
$\mathrm{~T}_{\mathrm{I}(\mathrm{s})}$ & Mean & $3.77 \pm 1.33$ & $3.09 \pm 0.61$ \\
$\mathrm{~T}_{\mathrm{E}(\mathrm{s})}$ & CV & $0.65 \pm 0.13$ & $0.63 \pm 0.11$ \\
& Mean & $2.18 \pm 0.67$ & $2.56 \pm 0.61$ \\
$\mathrm{~T}_{\mathrm{I} / \mathrm{T} T \mathrm{~T}}$ & CV & $0.72 \pm 0.13$ & $0.63 \pm 0.12$ \\
& Mean & $0.61 \pm 0.08$ & $0.54 \pm 0.06$ \\
Amplitude* & SD & $0.22 \pm 0.03$ & $0.22 \pm 0.03$ \\
& Mean & $2.33 \pm 1.01$ & $2.86 \pm 0.71$ \\
Time to peak AMP/T & CV & $0.38 \pm 0.10$ & $0.31 \pm 0.10$ \\
& Mean & $0.76 \pm 0.10$ & $0.83 \pm 0.09$ \\
Mean AMP/T & SD & $0.28 \pm 0.04$ & $0.25 \pm 0.05$ \\
& Mean & $1.37 \pm 0.62$ & $1.61 \pm 0.43$ \\
Peak AMP/T & CV & $0.70 \pm 0.14$ & $0.72 \pm 0.10$ \\
& Mean & $3.35 \pm 1.32$ & $4.07 \pm 1.04$ \\
R-R interval (s) & CV & $0.51 \pm 0.12$ & $0.57 \pm 0.12$ \\
& Mean & $0.52 \pm 0.05$ & $0.54 \pm 0.05$ \\
& CV & $0.12 \pm 0.04$ & $0.11 \pm 0.03$ \\
& Irregularity & $0.04 \pm 0.03$ & $0.04 \pm 0.01$ \\
\hline
\end{tabular}

Values expressed as \pm SD.

* Amplitude $(\mathrm{AMP})=$ respiratory inductance plethysmography waveform sum signal.
Table 4. Raw data from 47 Rett cases and 47 matched controls for the first five breaths after a breathhold

\begin{tabular}{llcc}
\hline \multicolumn{1}{c}{ Variable } & Measures & Rett cases & Controls \\
$\mathrm{T}_{\text {Tот }(\mathrm{s})}$ & Mean & $2.18 \pm 0.48$ & $2.49 \pm 0.42$ \\
& CV & $0.42 \pm 0.09$ & $0.32 \pm 0.07$ \\
& Irregularity & $0.42 \pm 0.12$ & $0.31 \pm 0.09$ \\
$\mathrm{~T}_{\mathrm{I}(\mathrm{s})}$ & Mean & $1.06 \pm 0.26$ & $1.08 \pm 0.22$ \\
& $\mathrm{CV}$ & $0.58 \pm 0.14$ & $0.47 \pm 0.12$ \\
$\mathrm{~T}_{\mathrm{E} \mathrm{(s)}}$ & Mean & $1.13 \pm 0.28$ & $1.41 \pm 0.24$ \\
& CV & $0.54 \pm 0.10$ & $0.43 \pm 0.08$ \\
$\mathrm{~T}_{\mathrm{I} / \mathrm{T}_{\text {TOT }}}$ & Mean & $0.48 \pm 0.04$ & $0.44 \pm 0.02$ \\
& SD & $0.14 \pm 0.02$ & $0.13 \pm 0.02$ \\
Amplitude* & Mean & $1.26 \pm 0.59$ & $1.16 \pm 0.13$ \\
& CV & $0.10 \pm 0.04$ & $0.10 \pm 0.04$ \\
Mean AMP/T $_{\mathrm{I}}$ & Mean & $1.40 \pm 0.47$ & $1.23 \pm 0.20$ \\
& CV & $0.62 \pm 0.12$ & $0.58 \pm 0.11$ \\
Peak AMP/T & Mean & $2.45 \pm 0.85$ & $2.16 \pm 0.35$ \\
& CV & $0.58 \pm 0.12$ & $0.58 \pm 0.12$ \\
R-R interval (s) & Mean & $0.50 \pm 0.05$ & $0.54 \pm 0.05$ \\
& CV & $0.10 \pm 0.04$ & $0.11 \pm 0.03$ \\
& Irregularity & $0.03 \pm 0.02$ & $0.04 \pm 0.02$ \\
\hline
\end{tabular}

Values expressed as \pm SD.

* Amplitude $(\mathrm{AMP})=$ respiratory inductance plethysmography waveform sum signal. 